Artigos

\title{
A cobertura da mídia impressa e o enquadramento das favelas cariocas na linguagem da violência urbana
}

\section{The coverage of press and the framing of Rio's favelas in the language of urban violence}

\author{
Luis Claudio Palermo*
}

\begin{abstract}
Resumo: A questão fundamental para o artigo é comparar as coberturas dos jornais impressos Extra e $O$ Globo acerca do início da ocupação policial realizada na favela Santa Marta. Visa-se, com isso, mostrar uma similaridade geral e algumas diferenças nos trabalhos desses veículos. A linha de raciocínio e argumentação é a relação entre os discursos das mídias em voga e as pressões sociais que contribuem para conformar tais discursos. Nesse sentido, é postulado que as diferenças nas coberturas podem ser apreendidas partindo do vínculo entre os discursos dos periódicos e as expectativas que essas mídias nutrem em relação às percepções dos leitores. Como semelhança geral, identifica-se o enquadramento preponderante das reportagens na ocupação militar da favela. Para explicar essa similaridade entre os impressos, invoca-se o casamento entre os discursos da imprensa e as representações gerais da sociedade sobre a ligação das favelas cariocas com a linguagem da violência urbana. Desse modo, é defendido que as mídias emprestam uma característica específica à referida linguagem ao incorporar, acriticamente, informações, dados, explicações e representações provenientes dos integrantes do governo. Palavras-chave: Mídia impressa. Favelas cariocas. Linguagem da violência urbana. Sociologia e imprensa. Unidades de Polícia Pacificadora (UPP).
\end{abstract}

Abstract: The aim of this article is to compare the covers of printed newspapers $O$ Globo and Extra about the beginning of the police occupation of the favela Santa Marta. The aim is to show a general similarity and some differences in the approach of these vehicles. The line of reasoning and argument is the relationship between the discourses of media in vogue and social pressures which contribute to conform such speeches. Therefore, it is postulated that the differences in coverage of the newspapers can be dimensioned starting from the link between the discourses of each newspaper and expectations that these media have in relation to perceptions of their readers. As a general similarity, the investigation has identified the military occupation of the favela as the preponderant framework of the news. To explain this similarity between both vehicles, the text invokes the link between the discourses of the press and the general representations of society about the

\footnotetext{
* Doutor em Ciências Sociais pela Universidade do Estado do Rio de Janeiro (Uerj, Rio de Janeiro, RJ, Brasil), doutorando no PPG em História da mesma universidade <luisclaudio72@ gmail.com>.
}

Civitas, Porto Alegre, v. 18 , n. 1 , p. 212-236, jan.-abr. 2018

Exceto onde especificado diferentemente, a matéria publicada neste periódico

é licenciada sob forma de uma licença

Creative Commons Attribution-NonCommercial-NoDerivatives 4.0 International License 
connection of Rio's favelas with the language of urban violence. Thus, it is argued that the media offers a specific characteristic to that language by uncritically incorporating information, data, explanations and representations from the government officials. Keywords: Press. Rio's favelas. Language of urban violence. Sociology and press. Unidades de Policia Pacificadora (UPP).

Resumen: El objetivo fundamental del artículo es comparar las coberturas de los periódicos impresos Extra y $O$ Globo acerca del inicio de la ocupación policial realizada en la favela Santa Marta. Se pretende, con ello, mostrar una similitud general y algunas diferencias en los trabajos de esos vehículos. La línea de raciocinio y argumentación es la relación entre los discursos de los medios en boga y las presiones sociales que contribuyen a conformar tales discursos. En este sentido, se postula que las diferencias en las coberturas pueden ser aprehendidas partiendo del vínculo entre los discursos de los periódicos y las expectativas que esos medios de comunicación nutren en relación a las percepciones de los lectores. Como similitud general se identifica el encuadramiento preponderante de los reportajes en la ocupación militar de la favela. Para explicar esta similitud entre los impresos se invoca el matrimonio entre los discursos de la prensa y las representaciones generales de la sociedad sobre la conexión de las favelas cariocas con el lenguaje de la violencia urbana. De este modo, se defiende que los medios prestan una característica específica al referido lenguaje al incorporar, acriticamente, informaciones, datos, explicaciones y representaciones provenientes de los integrantes del gobierno.

Palabras clave: Medios impresos. Favelas cariocas. Lengua de la violencia urbana. Sociología y prensa. Unidades de Policía Pacificadora (UPP).

\section{Introdução}

Em 20 de novembro de 2008, os jornais impressos Extra e $O$ Globo noticiaram que a Polícia Militar do estado do Rio de Janeiro havia ocupado a favela Santa Marta no dia anterior. Ambos periódicos divulgaram que as informações providas pelos integrantes do governo eram, basicamente, que se pretendia promover um "choque de ordem" e prender o chefe do tráfico de drogas na localidade.

Transcorrido pouco mais de uma semana, a imprensa atualizou as notícias, informando que o governo havia decidido pela manutenção da ocupação. Além disso, reportou que seria colocado em prática um novo modelo de policiamento na favela. O jornal $O$ Dia, por exemplo, publicou no título de uma matéria que o "Morro Dona Marta"1 seria o primeiro a receber uma "polícia comunitária" (O Dia, 28 nov. 2008, p.11). O Extra e $O$ Globo noticiaram que o governo

\footnotetext{
${ }^{1}$ Nas matérias jornalísticas que evidenciaram a ocupação da favela Santa Marta, os periódicos, não raramente, referem-se à favela como Morro Dona Marta. Mello e Cunha (2011, p. 377-379) esclarecem essa polêmica, mostrando a disputa em torno do nome.
} 
programava inaugurar uma Companhia da Polícia Militar na favela ( $O$ Globo, 28 nov. 2008, p. 15; Extra, 28 nov. 2008, p. 12).

Nos primeiros dias dessa ocupação, as poucas matérias jornalísticas refletiam um clima de indefinição e, sobretudo, de exiguidade de informação provida pelo governo do Rio de Janeiro. A partir do mês de dezembro, ou seja, quase duas semanas depois da ocupação policial, integrantes da equipe do governo passaram a oferecer, gradativamente, informações e seus objetivos para explicar a presença ostensiva da Polícia Militar na localidade. Sabe-se, hoje, que esse modelo acabou ganhando notoriedade e, no início do ano de 2009, transformou-se no conhecido programa das Unidades de Polícia Pacificadora (UPPs). ${ }^{2}$ Dessa forma,

Olhando em retrospectiva, sabemos que os desdobramentos desse evento [a ocupação da favela Santa Marta] produziram o surgimento das Unidades de Polícia Pacificadora (UPPs), projeto que vem pautando o debate sobre as políticas de segurança pública no Rio de Janeiro, bem como a relação entre a cidade e as favelas no Rio. As discussões sobre o tema tendem a se concentrar nas avaliações sobre o impacto das UPPs na sociabilidade carioca e na rotina dos cidadãos, moradores ou não de favelas. Parte importante desse debate é travada nas páginas dos jornais, que têm dedicado cada vez mais espaço ao tema da segurança pública. Nesse sentido, são peça essencial no jogo político que aumenta o sucesso ou o fracasso da iniciativa, ajudando a compor o vocabulário acionado nessa argumentação (Rocha; Palermo, 2015, p. 25, grifos meus).

As mídias se tornaram, então, um canal privilegiado de divulgação do programa das UPPs (Almendra, 2014, p. 64). E tal programa ganhou, à época, "centralidade no debate sobre segurança pública no Brasil", recebendo “destaque de [em] inúmeras reportagens" (Menezes, 2014, p. 665). Além disso, cumpre frisar que a imprensa tem se tornado, crescentemente, uma esfera pela qual, também (não somente) as políticas públicas são executadas e formuladas (Fausto Neto, 1999, p. 137; Ramos; Paiva, 2007, p. 21-22). Assim, por meio desses veículos, a linguagem da violência urbana ${ }^{3}$ se organiza e reverbera socialmente, adquirindo um cariz.

\footnotetext{
${ }^{2}$ Para mais informações sobre o programa das UPPs, sugere-se, apenas como alguns exemplos, que sejam consultados os seguintes textos: Burgos et al. (2011, p. 49-98), Mello e Cunha (2011, p. 371-375), Rodrigues e Siqueira (2012, p. 9-52), Cano et al. (2012, p. 21-29), Palermo (2014b, p. 1-28).

3 A linguagem da violência urbana pode se apresentar por meio de diferentes repertórios (Machado da Silva, 2010, p. 293). Cumpre esclarecer, desde já, que, a partir de Machado da Silva $(2010 ; 2011 ; 2012)$, a referida linguagem é tratada, neste artigo, como um constructo
} 
Entretanto, as mídias não apresentam um discurso homogêneo (Porto, 2009, p. 226). Tanto seus temas como suas abordagens e formas de escrita têm intrínseca relação com o diálogo que esses veículos estabelecem com seus leitores (Silva, 2010, p. 154-158). Em outros termos, o que é veiculado nas mídias não é fruto de uma posição normativa e meramente definida por sua editoria ou por seus profissionais. Logo, o que é divulgado é resultado de uma relação dialógica entre os veículos de mídia e o público que acessa as informações providas por eles.

Visa-se realçar com essas considerações que na divulgação de notícias há escolhas, tematizações, abordagens etc., que são produções realizadas pelas mídias, mas que contemplam, em seu núcleo, uma necessidade de comunicação e interação com o público que acessa o conteúdo produzido. Trata-se de uma necessidade de ajuste "[...] às condições sociais de recepção de seu discurso". Assim, os jornalistas se encontram em face da constante necessidade de modulação, ajuste e adaptação de seus discursos, a fim de "[...] estabelecer uma relação de consonância entre os interesses do veículo que representam e os do seu público-alvo" (Silva, 2010, p. 154).

Portanto, os veículos de mídia mantêm com seus leitores uma relação dialética na qual tanto influenciam seu público e são influenciados por ele. Em razão disso, é crucial destacar que os jornalistas (e os veículos de mídia) produzem seu trabalho a partir de um horizonte de expectativas do que é considerado, pela própria editoria do jornal, como a grande maioria de seu público leitor (Fausto Neto, 1999, p. 12-13).

Diante do exposto, pode-se afirmar que um dos principais trabalhos realizados pelas mídias é organizar a percepção social (Cevis, 2011, apud Rocha e Palermo, 2015, p. 26), repercutindo representações sociais (Porto, 2009, p. 213; Thompson, 2014, p. 156), ajustando-se às "vozes dos diferentes atores sociais e políticos" (Almendra, 2014, p. 65) que estão envolvidos, de alguma forma, no circuito de produção, circulação e consumo dos documentos (Mauad e Cavalcante, 2013b) produzidos pela imprensa. Deve-se registrar, de forma introdutória, que essa é a concepção que orienta os princípios metodológicos

discursivo organizado para representar e conferir sentido ao debate em torno da segurança e da ordem pública, num período em que a violência urbana apresentou crescimento constante, ou seja, a partir de meados dos anos 1980. O ponto fulcral que é incorporado na discussão aqui estabelecida é a centralidade que as favelas ganham, notadamente no tocante ao problema da violência urbana. Ora, num período em que se deveria ampliar cada vez mais a linguagem dos direitos para todos moradores da cidade, testemunhou-se o enquadramento das favelas na gramática da violência urbana, que, em síntese, associa difusa e imprecisamente esses lugares e seus moradores aos traficantes de drogas que atuam nessas localidades (Rocha e Palermo, 2015, p. 26), dificultando o direito das favelas à cidade e, por conseguinte, a ação política de seus moradores. 
e as referências teóricas utilizados na análise do material empírico de pesquisa.

Feitas essas considerações introdutórias e teóricas, cumpre expor que o ponto de partida da questão pesquisada e discutida neste artigo se relaciona com as semelhanças e diferenças presentes no trabalho dos veículos de mídia e sua ligação com a percepção da sociedade acerca do lugar das favelas na "linguagem da violência urbana" (Machado da Silva, 2010, p. 283). O exercício principal aqui realizado é estabelecer uma comparação entre dois jornais impressos que fazem parte de uma mesma organização. Objetivase, com isso, identificar proximidades e distâncias entre eles, no tocante à cobertura da ocupação policial da favela Santa Marta. Em decorrência dessa análise comparativa, intenta-se tanto discutir questões teórico-metodológicas relacionadas ao material de pesquisa, quanto, por conseguinte, mostrar como parcela da imprensa empresta um cariz específico e singular à linguagem da violência urbana.

Convém aduzir que os veículos selecionados para esta empreitada foram os jornais impressos Extra e $O$ Globo, que fazem parte da empresa Infoglobo. ${ }^{4}$ Para o trabalho desenvolvido no artigo, foram analisadas doze reportagens do primeiro periódico e dezesseis do segundo, no período compreendido entre 20 de novembro e 22 de dezembro de 2008 , o que corresponde a pouco mais de um mês entre a ocupação policial da favela Santa Marta e a inauguração de uma Companhia de Policiamento Comunitário na localidade, que se tornou a base para a implementação da Unidade de Polícia Pacificadora (cf. Palermo, 2014a, p. 117-118). Foi definido um escopo pequeno de tempo para que se pudesse fazer uma análise do discurso das mídias selecionadas de forma intensiva e detalhada, a fim de produzir resultados comparativos significativos e específicos. ${ }^{5}$

As discussões acerca das diferenças e semelhanças nos discursos das referidas mídias serão realizadas em três seções fundamentais, além da introdução e considerações finais. A primeira seção registra especificamente as diferenças entre as coberturas dos periódicos, apontando singularidades concernentes à forma de escrita, abordagem de conteúdo e, sobretudo, no que tange ao enquadramento temático realizado pelas reportagens; a segunda propõe explicações teórico-metodológicas para as referidas diferenças

\footnotetext{
${ }^{4}$ Empresa do grupo Globo cuja função é, sinteticamente, organizar e coordenar as publicações dos jornais O Globo, Extra, Expresso.

${ }^{5}$ Os resultados que são discutidos neste artigo têm relação adicional com um conjunto de reflexões desenvolvido em outras duas pesquisas que realizei. Essas pesquisas deram origem a outros trabalhos já publicados (Palermo, 2013; 2014a; 2014b).
} 
registradas nos trabalhos das mídias pesquisadas. Nesse sentido, o foco é relacionar muito especialmente essas dessemelhanças ao diálogo realizado pelos jornais investigados com as expectativas projetadas de seu públicoalvo, tomando essa questão como um exemplo possível que contribui para pensar como as pressões discursivas externas (do público leitor) exercem, em alguma medida, influência no trabalho dessas mídias; a terceira seção promove uma inflexão e coloca em discussão, primordialmente, o porquê da semelhança entre as coberturas, a fim de relacioná-las ao papel desses veículos na caracterização singular e na reverberação da linguagem da violência urbana.

\section{As diferenças na cobertura das mídias do Infoglobo: Extra e $O$ Globo}

Os jornais impressos Extra e $O$ Globo são dois produtos importantes da empresa Infoglobo. Segundo dados providos pelas próprias editorias, é importante mencionar que - no período em que esta pesquisa se realizou - o primeiro periódico atinge mais substancialmente as classes sociais B e C, com $51 \%$ de seus leitores pertencendo especificamente à classe $\mathrm{C}$. O perfil etário dos leitores é bem distribuído, mas apresenta maior incidência na faixa que varia entre 30 e 39 anos. Além disso, esse impresso é mais lido por pessoas que possuem ensino médio, perfazendo um total de $49 \%$, do que por aquelas que têm curso superior, que correspondem a apenas $17 \%{ }^{6}$

$O$ Globo, por sua vez, atinge - considerando-se também o período em que a pesquisa se realizou - principalmente a classe social $\mathrm{B}$, totalizando $55 \%$ nessa faixa. Ademais, o perfil etário de seu público é bem distribuído. Apesar disso, cumpre informar que a maioria de seus leitores se situa na linha acima dos 60 anos. Deve-se acrescentar também que a maioria do seu público tem curso superior, alcançando um total de 49\%. ${ }^{7}$ Em outros termos:

O jornal O Globo fala para as elites, as classes A e B (categorias de renda, em última análise), que representam $78 \%$ do seu público leitor. Já os leitores do jornal Extra formam um público um pouco mais diferenciado, porém concentrado no outro extremo do continuum de renda, com 57\% nas classes C, D e E (Almendra, 2014, p. 72).

Uma vez que esses veículos pertencem ao mesmo grupo, suas reportagens exibem similaridades muito visíveis, principalmente no caso das matérias

\footnotetext{
$6<$ www.infoglobo.com.br/Anuncie/ProdutosDetalhe.aspx?IdProduto=92> (11 jun. 2015).

$7<$ www.infoglobo.com.br/Anuncie/ProdutosDetalhe.aspx?IdProduto=91> (11 jun. 2015).
} 
que são produzidas por um mesmo (ou uma mesma) repórter, com vistas à utilização e publicação por ambos os periódicos. Inobstante as semelhanças entre as matérias produzidas num e noutro, deve-se ressaltar que há diferenças de estilo de linguagem, de enquadramento temático, bem como de seleção e apresentação de seus conteúdos. Ainda que essas distinções se apresentem algumas vezes de forma sutis, há que se destacar que contribuem para se pensar o papel e atuação de cada veículo na vida social e política, assim como, por outro lado, a influência da sociedade em cada um deles.

Nesta seção, três diferenças são primordialmente tratadas: a primeira é concernente ao estilo de linguagem utilizado por cada mídia; a segunda é atinente ao enquadramento temático realizado por elas; por fim, analisa-se em que medida há diferenças na apresentação de conteúdo de cada impresso examinado.

No que tange à primeira diferença acima arrolada, pode-se propor que $O$ Globo, de forma geral, apresenta uma linguagem com um cariz mais cerimonioso e formal, enquanto o Extra se caracteriza por um estilo que prima pela leveza e coloquialismo. Ademais, este último veículo apresenta um conteúdo mais reduzido do que aquele. Destarte, as matérias publicadas no Globo tendem a pormenorizar as informações e a acrescentar mais dados ao conteúdo publicado do que as do Extra. Um exemplo contundente dessa diferença pode ser registrado na cobertura realizada por esses jornais em reportagens que trataram da possibilidade da oferta de serviços legalizados na Santa Marta, em consequência da ocupação policial nessa favela. Seguem trechos das matérias, com as diferenças nuançadas em itálico:

[Título] Morro Dona Marta começa a receber serviços [Subtítulo] Companhia telefônica instala fios para novas linhas e moradores compram pacotes para TV a cabo regularizada.

(O Globo, 5 dez. 2008, p. 17, grifos meus).

[Título] A legalidade agora sobe o Dona Marta [Subtítulo] Empresas tomam o lugar de 'gatos' (Extra, 5 dez. 2008, p. 13, aspas do próprio jornal e grifos itálicos meus).

Ambos os periódicos transmitem informações bem similares acerca da oferta de serviços na favela. Esse é o eixo central das matérias. A despeito disso, a reportagem do Globo, em seu todo, tem uma expressão mais formal e apresenta informações gerais e mais detalhadas do que o Extra, registrando os depoimentos de moradores sobre a oferta desse tipo de serviço e atualizando a situação da ocupação policial na localidade. 
A reportagem apresentada pelo Extra, em sua totalidade, é mais concisa, objetiva e, convém destacar, tem um tom mais impactante em seu título (quase sensacionalista): "A legalidade agora sobe o Dona Marta". Vale acrescentar que este último periódico se expressa numa linguagem mais popular, coloquial, que pode ser identificada, por exemplo, pela utilização da palavra "gatos" no subtítulo da matéria.

A segunda dessemelhança a ser destacada é bastante importante para se compreender as diferenças nos papéis sociais e políticos das mídias em apreço. Trata-se do enquadramento temático das reportagens. Convém esclarecer e aduzir que enquadramento é um conceito com muitas apropriações por parte de eminentes autores. "Ainda não existe, portanto, uma definição consensual sobre o que sejam os enquadramentos da mídia" (Porto, 2004, p. 77). Sendo assim, o conceito de enquadramento temático é compreendido, aqui, como a ideia que organiza o sentido do texto e "que atribui significados específicos aos eventos, tecendo uma conexão entre eles e definindo o caráter de controvérsias políticas" (idem, p. 81).

A principal diferença identificada nas reportagens publicadas pelas mídias pesquisadas é que $O$ Globo utiliza um enquadramento temático que coloca em evidência não somente a ocupação policial em si, mas também abre espaço para informar acerca da promoção de serviços sociais decorrentes dessa ocupação na favela Santa Marta. O Extra, por seu turno, enquadra as reportagens, de modo preponderante, na ocupação policial e na manutenção da ordem por parte do novo modelo de policiamento que estava sendo colocado em experimentação.

Comparativamente, portanto, as matérias do Globo retratam uma ideia central organizadora dos acontecimentos cujo núcleo é a presença policial (ocupação militar) para viabilizar a oferta de serviços na favela (ocupação social). Este periódico não deixa de dar valor central à ocupação policial, mas aborda também as promessas governamentais de promoção de benefícios sociais para a favela. O enquadramento do Extra diferencia-se por situar e valorizar mais a presença policial e seu controle militar na localidade, avançando qualitativamente menos na pauta relativa à promoção de benefícios sociais (ou quaisquer outras pautas), reforçando, desse modo, a ocupação como ideia que preside suas abordagens.

O Editorial do Globo pode sintetizar o que se está colocando em discussão aqui. Conforme apresentado a seguir, o enquadramento da coluna opinativa está orientado, de forma preponderante, para a aprovação da ocupação policial realizada pelo estado (ênfase na ocupação militar). Isso pode ser notado no título e num trecho do texto em que é usado um argumento que expõe a posição geral e pública dos editores: 
[Título do Editorial] Ocupação real

É no mínimo animadora a afirmação do governador Sérgio Cabral de que o tráfico no Dona Marta está aniquilado. Após uma ocupação que começou na segunda quinzena de novembro, com efetivos da Polícia Militar, o governo, de acordo com Cabral, sufocou o movimento de compra e venda de drogas, esteio econômico das quadrilhas que se sucediam no comando das atividades criminosas da favela, encurtou gradativamente as áreas subjugadas pelos traficantes e, por fim, expulsou os bandidos da região.

[...] A lógica dessa política é cristalina: diferentemente da tática de enxugar gelo empregada em outras favelas, onde o poder público promove invasões por meio de seu braço armado e bate em retirada, deixando a região novamente à mercê do crime, $a$ opção pela ocupação em tempo integral mantém a área sob controle do estado. Exemplo que justifica a nova orientação em vigor no Dona Marta é a favela Tavares Bastos, onde a presença constante de efetivos do Bope igualmente logrou desalojar os bandidos. A reconquista do Dona Marta não decorre de táticas sofisticadas de enfrentamento do crime organizado. O governo, neste caso, apenas seguiu o mais elementar manual, criando um filtro nos acessos ao morro e mantendo policiais lá em cima para garantir a segurança dos moradores [...] (O Globo, 3 dez. 2008, p. 6, grifos meus).

Não obstante o que foi apresentado acima, que contém um sentido orientado para o controle militar, há a afirmação, no final do Editorial, de que o governo estava em vias de estender para outras favelas o modelo de ocupação colocado em experimentação na Santa Marta e a sugestão de que esse deveria ser:

[...] o primeiro e efetivo passo para a ocupação definitiva dessas áreas através da oferta de serviços públicos até aqui praticamente inexistente nas comunidades. Somente assim, de acordo com essa perspectiva, o estado de direito voltará a vigorar em toda a cidade (Idem, grifos meus).

Em acréscimo, há que se destacar uma última diferença identificada na pesquisa, a que concerne à seleção e apresentação de conteúdo que faz parte das reportagens publicadas pelos impressos examinados. Essa distinção alude ao fato de o jornal $O$ Globo utilizar uma seleção de conteúdo que mostra mais significativamente as questões ligadas ao impacto da ocupação militar (policial) no entorno da Santa Marta do que o Extra. A ênfase nos benefícios da presença policial para a região próxima à favela marca, dessa forma, outra diferença de valorização de conteúdo informativo entre as mídias pesquisadas. 
A partir da leitura e análise dos impressos investigados, pode-se assinalar, destarte, que $O$ Globo publica mais substancialmente informações que apresentam o ponto de vista e preocupações de moradores das ruas próximas à referida favela, de comerciantes do entorno e de profissionais ligados ao ramo imobiliário do que o Extra. O realce do Globo recai ora na queda dos roubos e furtos na região, ora na valorização dos imóveis ocorrida no bairro em que a favela está situada. Deve-se explicitar que o Extra não deixa de prover essas informações, mas não as aborda com a mesma intensidade e frequência que aquele impresso.

À guisa de fundamentação do que foi registrado, cabe destacar uma matéria produzida poucos dias após a criação da Companhia de Policiamento Comunitário na favela. Nessa reportagem, $O$ Globo ressalta os ganhos obtidos tanto por moradores da Santa Marta como pelo setor imobiliário da região de Botafogo. Convém registrar que os ganhos do setor imobiliário correspondem à parte mais visível, constituindo-se no seu enquadramento matricial. Segue um trecho:

[Título] Ação no Dona Marta aquece mercado imobiliário [a ação na favela Dona Marta refere-se à ocupação policial na favela]

[Subtítulo] A voz do morro - Segundo corretores, com o fim do tráfico de drogas na favela, procura por imóveis em Botafogo cresceu $30 \%$.

[Excerto do texto que compõe a reportagem] Os ventos que sopram a favor dos moradores do Morro Dona Marta, em Botafogo, desde a sua ocupação pela polícia, há um mês, também embalam as vendas de imóveis de classe média no entorno da favela. Com o fim do tráfico de drogas, corretores da região avaliam que houve um aumento na procura de apartamentos no bairro de $25 \%$ a $30 \%$. Segundo Nelson Freitas, diretor regional da [empresa corretora de imóveis], um apartamento de três quartos e garagem na Rua da Matriz, em frente ao morro, que custava $\mathrm{R} \$ 300$ mil, hoje é vendido rapidamente por R\$ 420 mil. [...] (O Globo, 21 dez. 2008, p. 17, grifos meus).

É importante chamar a atenção que o jornal Extra, no mesmo dia 21 de dezembro, também publicou uma reportagem sobre a favela. Tal matéria apresentava uma abordagem deveras diferente da que foi produzida pelo Globo. A reportagem daquele impresso tratava principalmente da melhoria na rotina dos moradores da Santa Marta, sublinhando, na perspectiva do jornal, a "paz" que estava cada vez mais presente na localidade e prevendo um Natal com esperança renovada para os moradores (Extra, 21 dez. 2008, p. 13). 


\section{Influências do circuito social das mídias impressas na forma de comunicação realizada pelo Extra e $O$ Globo}

Na qualidade de uma instituição social, as mídias não falam solitariamente; ao contrário, sua forma de comunicar dialoga com a sociedade. Por isso, seus discursos devem ser analisados a partir da rede que contempla todo um circuito social (cf. Mauad; Cavalcante, 2013a, 2013b; Fausto Neto, 1999) que está relacionado, pelo menos, com dois fatores.

O primeiro se refere às condições de produção da mídia, que têm ligação com uma "cultura profissional [das pessoas que atuam na imprensa], entendida como um emaranhado de estereótipos, representações sociais e rituais relativos às funções dos meios de comunicação de massa e dos jornalistas" (Aguiar, 2006, p. 78).

O segundo fator remete à circulação do produto final da mídia, o que envolve o cuidado com o discurso colocado em ação, de modo que este não esteja em dissonância com as expectativas do seu público leitor (cf. Silva, 2010, p. 154-158; Fausto Neto, 1999, p. 12-13) nem dos anunciantes e da editoria da empresa (cf. Bourdieu, 1997, p. 19-20). ${ }^{8}$

Compreender o discurso dos jornais impressos envolve, portanto, analisar seu conteúdo para além da simples informação textual. Deve-se incluir o texto numa teia de relações que, ao cabo, contribui para modular as escolhas dessas mídias e o próprio formato de apresentação das reportagens (cf. Fausto Neto, 1999, p. 7-14).

Nessa linha, as diferenças apontadas na seção anterior sobre as coberturas do Extra e do Globo têm ligação principalmente com um conjunto de expectativas sociais que contribuem, em alguma medida, para a modulação dos discursos dos impressos, visto que as notícias reportadas não são meros resultados de uma realidade dada (Silva, 2011, p. 2) nem se configuram como relatos verdadeiros, objetivos e fieis dos fatos. Em outros termos:

Pela teoria do newsmaking, o jornalismo é um dispositivo de construção da realidade; logo, não pode ser mero reflexo do real. Ou seja, as notícias - e também as reportagens - não refletem os acontecimentos que se dão a ver, mas são antes de tudo construções

\footnotetext{
${ }_{8}^{8}$ Pode-se afirmar que o circuito social que recobre as mídias é muito complexo. Nesta seção, o enfoque prioriza o trabalho com uma escolha analítica presidida pela relação entre escrita e o horizonte de circulação da mídia impressa, tendo especial atenção às expectativas do públicoalvo (leitor) dos impressos pesquisados. Reconhece-se, dessa forma, que a ampliação do escopo tornaria a pesquisa deveras extensa, o que inviabilizaria sua proposta de ser um artigo. No entanto, a aposta subjacente é que o exercício realizado não compromete a veracidade dos argumentos e dos resultados apresentados, podendo oferecer uma contribuição acadêmica.
} 
narrativas que produzem condições de possibilidades através dos quais a realidade se dá a conhecer. A noticiabilidade é constituída pelo conjunto de requisitos que se exigem dos acontecimentos tanto do ponto de vista da estrutura do trabalho nos jornais como também do profissionalismo dos jornalistas - para que possam adquirir a existência pública na formação discursiva denominada notícia (Aguiar, 2006, p. 81).

Em vista dessas considerações, pode-se propor uma explicação para a primeira diferença tratada na seção anterior, a que remete ao estilo de linguagem utilizado por cada mídia. ${ }^{9}$ É possível depreender e interpretar, pois, que a forma de escrita mais coloquial e mais leve do jornal Extra, conforme identificado na pesquisa realizada aqui e exposto na seção anterior, tem alguma ligação com o horizonte de expectativas da editoria do periódico acerca de quem é seu leitor médio, ou seja, um tipo idealizado que a mídia procura atender (Silva, 2010, p. 97-98). ${ }^{10}$

Nesse sentido, cabe lembrar que o Extra se apresenta como o jornal que é mais lido neste país e "[...] seus leitores são atraídos por um veículo que sempre busca oferecer o melhor conteúdo, novos cadernos, produtos e serviços que facilitam a vida das pessoas". ${ }^{11}$ Logo, pode-se inferir que o uso de uma exposição mais informal, menos cerimoniosa (com menos pompa e etiqueta), é um recurso que permite a este jornal um diálogo mais profícuo e fecundo com uma grande massa de leitores. Parece que esse é um recurso necessário a um periódico que se intitula como o mais lido do Brasil. Assim, por essa perspectiva, a chave do bom relacionamento com o leitor seria produzir um periódico com uma linguagem mais simples e acessível possível porque o jornal Extra é o mais lido de todos. ${ }^{12}$

\footnotetext{
${ }^{9}$ A análise que fiz nesta pesquisa, - sobretudo a que reverbera na explicação empregada neste ponto do artigo -, visou interpretar os dados providos pela editoria dos jornais (no sítio do Infoglobo) não somente considerando o que eles informam/descrevem, mas também submetendo-os ao escrutínio reflexivo do pesquisador acerca do que reverbera na prática, ou seja, no que se pode identificar na leitura dos diários. Com isso, visei concatenar teoria e prática, ou seja, fazer uma relação entre o que é informado pelas editorias de cada jornal e o que se realiza na prática (na escrita dos jornais). Além disso, busquei interpretar como a escrita dos jornais tem uma conexão com o público que é projetado como possível leitor.

${ }^{10}$ Inobstante as pressões e negociações que cercam os discursos das mídias (escolha analítica feita aqui), há que se advertir, de forma reiterada, que tanto a atuação social da imprensa como sua ação política não se restringem meramente em organizar e difundir algumas percepções sociais. Logo, sua atuação não é totalmente determinada pelas pressões exógenas. O público leitor "mantém, ainda que não declaradamente, uma relação dialética com o jornal, na qual tanto sofre quanto produz efeitos" (Silva, 2010, p. 98, grifos meus). Ao recortar essa perspectiva, estou, aqui, fazendo um exercício analítico que procura concatenar teoria e prática, de modo a mostrar uma possibilidade de enxergar a relação entre os jornais investigados e seu público.

${ }_{11}<$ www.infoglobo.com.br/Anuncie/ProdutosDetalhe.aspx?IdProduto $=92>(21$ jul. 2015).

${ }^{12}<$ www.infoglobo.com.br/Anuncie/ProdutosDetalhe.aspx?IdProduto $=92>(21$ jul. 2015).
} 
Analogamente, é factível depreender que $O$ Globo também procura se aproximar ao máximo de seu público-alvo ao se portar, por outro ângulo, de uma forma mais formal, mais cerimoniosa (mais rigorosa na observância das regras de polidez e de etiqueta) do que o Extra. Por isso, argumenta-se aqui que seu tom mais formal se encaixaria numa perspectiva cuja referência comunicativa é formada por leitores definidos pelo próprio jornal como "formadores de opinião"13 (deliberadamente um público mais seleto, por isso, um tipo de mensagem mais diretiva e não tão excessivamente abrangente como a do jornal Extra).

Cumpre acrescentar que as diferenças de enquadramento temático e de seleção de conteúdo que foram publicados pelas mídias pesquisadas, conforme explicitado na seção anterior, podem ser compreendidas acompanhando-se o circuito social desses jornais, não somente se limitando às questões concernentes à produção de cada um deles. Assim, sugere-se, aqui, que essa explicação acerca das dessemelhanças identificadas nos impressos deve ser centrada mais na recepção dos discursos dos periódicos do que na sua proposta editorial de ser um veículo mais ou menos detalhado ou de ter maior/menor conteúdo.

Adotando-se essa perspectiva, é possível compreender que as divergências de enquadramento temático e de conteúdo (identificadas na seção anterior como segunda e terceira diferenças) não são contraditórias, haja vista que $O$ Globo, no tópico denominado "Hábitos de consumo dos leitores", ${ }^{14}$ que consta em sua própria página na internet, apresenta-se como "O jornal preferido dos formadores de opinião. Com colunistas renomados, o noticiário cobre os fatos mais importantes de maneira clara e objetiva". ${ }^{15}$ O Extra, por seu turno, é mais vago em sua definição final de um público receptor de seu conteúdo, pois informa, em seu sítio na página mundial de computadores, que "Nada é mais valioso para um jornal do que os seus leitores. Não é à toa que o Extra é o jornal mais lido do Brasil". ${ }^{16}$

Tomando por base a noção de "formador de opinião" assumida pelo Globo, cabe aduzir que a nova e atual abordagem jornalística sobre a violência urbana referencia-se, crescentemente, no que se chama de "coberturas segurança pública" (Silva, 2010, p. 99) ou nas "pautas sobre segurança pública" (Ramos e Paiva, 2007, p. 17). Essas novas coberturas se diferenciam do antigo jornalismo policial que primava pelo uso de "recursos sensacionalistas e noções apelativas" (idem, p. 15). Assim, algumas das atuais coberturas procuram fornecer, cada vez mais, a "apresentação de subsídios informativos [opinião

\footnotetext{
${ }^{13}<$ www.infoglobo.com.br/Anuncie/ProdutosDetalhe.aspx?IdProduto=91 $>(21$ jul. 2015).

${ }^{14}<$ www.infoglobo.com.br/Anuncie/ProdutosDetalhe.aspx?IdProduto $=91>(21$ jul. 2015).

${ }^{15}<$ www.infoglobo.com.br/anuncie/ProdutosDetalhe.aspx?IdProduto=91 $>$ (21 jul. 2015).

${ }^{16}<$ www.infoglobo.com.br/Anuncie/ProdutosDetalhe.aspx?IdProduto=92> (27 maio 2015).
} 
de especialistas] que contribuam para a adoção de medidas pró-ativas" (Silva, 2010, p. 100), o que é consoante com a expectativa do Globo em relação ao seu público-alvo, segundo o que foi explicitado acima.

Tendo por referência o impresso Extra e a ideia de que "o destaque jornalístico conferido a esta ou aquela ocorrência diz respeito não tanto ao fato noticiado em si, mas a quem se sente, direta ou indiretamente, afetado por ele" (idem, p.159, grifos meus), pode-se compreender que o fato desse periódico enquadrar suas reportagens sobre a ocupação da Santa Marta numa perspectiva militarizada, bem como de seu conteúdo ser menos detalhado em relação ao $O$ Globo, está em harmonia com sua expectativa de atingir um leitor mais genérico, vago.

Em razão do exposto, é possível inferir que $O$ Globo prima por ter uma cobertura de segurança pública mais detalhada e ampla, avançando no aprofundamento de algumas questões, porque objetiva dialogar com "formadores de opinião", ${ }^{17}$ pessoas que, na perspectiva do jornal, devem exigir a "apresentação de subsídios informativos" (Silva, 2010, p. 100). No caso do Extra, é possível interpretar que sua abordagem comunicativa é mais voltada para o atendimento de uma demanda mais universalmente projetada, em razão de este impresso não prover, em sua página na internet, uma definição clara de público-alvo nem do hábito de consumo de seus leitores.

Portanto, enquanto $O$ Globo parece se mostrar orgulhoso por se considerar o "jornal preferido dos formadores de opinião", ${ }^{18}$ o Extra mostra-se vaidoso por se intitular o impresso "mais lido do Brasil", ${ }^{19}$ por isso afirma que não há nada "mais valioso para um jornal do que os seus leitores", ${ }^{20}$ conferindo um sentido bastante impreciso a seu público.

Em termos sinópticos, $O$ Globo define um público-alvo mais específico, mas o Extra não. Logo, essas referências acabam tendo implicação em seus métodos de se comunicar. Tais nuanças podem não ser percebidas caso não se proceda ao exame da fonte discursiva em sua circulação social, pois:

Como uma teoria crítica da leitura, a contribuição da análise do discurso é mostrar que os modos de ver a realidade pela linguagem não são processos mecânicos de decodificação do sistema linguístico, mas é um processo dialógico em que o leitor, enquanto coenunciador, assume uma atitude responsiva dialogando como texto, respondendo ao desafio de interpretação que ele impõe (Brandão, 2013, p. 42, grifos meus).

\footnotetext{
$17<$ www.infoglobo.com.br/anuncie/ProdutosDetalhe.aspx?IdProduto=91> (21 jul. 2015).

$18<$ www.infoglobo.com.br/anuncie/ProdutosDetalhe.aspx?IdProduto=91 $>$ (21 jul. 2015).

${ }^{19}<$ www.infoglobo.com.br/Anuncie/ProdutosDetalhe.aspx?IdProduto=92> (27 maio 2015).

${ }^{20}<$ www.infoglobo.com.br/Anuncie/ProdutosDetalhe.aspx?IdProduto=92> (27 maio 2015).
} 


\section{A homologia identificada nas coberturas do Extra e do Globo: representações sociais sobre o lugar das favelas cariocas na linguagem da violência urbana}

Na pesquisa realizada em reportagens publicadas nos jornais em apreço é possível identificar uma similaridade marcante entre as duas coberturas: a ênfase dos enquadramentos temáticos de ambos recai sobre a ocupação militar (policial) da favela Santa Marta. Pretende-se, nesta seção, propor uma explicação para o fundamento basilar dessa homologia, explicitando como essa semelhança tem relação com a circulação dessas mídias, conforme assinalado na seção precedente. ${ }^{21}$

Sugere-se, de forma suplementar, que essa proximidade ou similitude apontada entre o Extra e $O$ Globo não se diferencia muito de algumas outras mídias de grande circulação (Silva, 2010, p. 160). Dessa forma, a semelhança identificada não tem ligação somente com o fato de ambos periódicos pertencerem a um mesmo grupo empresarial, ou seja, ancorarem-se, em sentido geral, numa mesma perspectiva endógena. Para se compreender essa aproximação entre as coberturas desses jornais, em seu sentido amplo, deve-se, sobretudo, voltar o olhar para as representações das favelas cariocas no tecido urbano, notadamente atentando para a conexão entre esses lugares de moradia e a linguagem da violência urbana.

Em razão do que foi postulado, cumpre expor, com mais minúcia, o que se entende por linguagem da violência urbana, na medida em que esse é um constructo que admite diferentes repertórios (Machado da Silva, 2010, p. 293). Essa explicação remete ao processo recente de construção da democracia brasileira cujo desenvolvimento se processou em concomitância ao crescimento da violência urbana. Segundo Peralva (2000), esse seria o paradoxo da história recente do Brasil.

A autora em apreço provê quatro fatores que visam explicitar o crescimento da violência urbana, no período de transição da ditadura governada por militares para a democracia, entre o final da década de 1970 e início dos anos 1980. Interessa, aqui, posicionar especialmente dois desses fatores. Um deles tem relação com a "Continuidade autoritária" (idem, p. 74), que corresponde à manutenção de princípios autoritários nas instituições

\footnotetext{
${ }^{21}$ Cabe destacar que esta seção mantém a linha argumentativa muito próxima da anterior: a relação entre produção midiática e as pressões que a expectativa da recepção social exerce sobre tal produção. No entanto, nesta seção amplia-se o enfoque porque parte-se do público leitor para as pressões discursivas que a sociedade como um todo exerce sobre a produção dos jornais impressos que fazem parte da pesquisa. Daí a ligação defendida entre a produção desses jornais com a linguagem da violência urbana.
} 
ligadas à ordem pública, como a Polícia Militar, por exemplo. Isso “explicava a persistência, no regime democrático nascente, de formas de funcionamento autoritário" (idem, p. 75-76). Outro aspecto importante invocado é a "noção de "autoritarismo socialmente implantado"" na sociedade brasileira. Segundo Peralva, "esse tipo de explicação foi reforçado por pesquisas que apontavam para uma opinião pública altamente favorável ao emprego de métodos violentos pela polícia, à instauração da pena de morte, ou ao recurso a métodos de justiça ilegal (idem, p. 76).

Além do crescimento dos índices de violência, no período mencionado, vale registrar que aumentou também a sensação de insegurança na cidade do Rio de Janeiro, tendo em vista a constituição de um cenário de medo que foi potencializado, sobretudo, por alguns episódios emblemáticos: arrastões, brigas em bailes funk e as chacinas da Candelária, de Vigário Geral e de Acari, entre outros (Leite, 2000, p. 74).

Especialmente a partir dos anos 1990, o Rio de Janeiro passou a ser representado não somente como um lugar violento, mas também como uma cidade partida entre favelas e asfalto. Destarte, a "representação do Rio de Janeiro como uma 'cidade partida' terminou [...] por reforçar os nexos simbólicos que territorializavam a pobreza e a marginalidade nas favelas cariocas" (idem).

Nessa conjuntura, os debates sobre a situação social da cidade passaram a incorporar "a metáfora da guerra de todos contra todos" como um operador lógico que ligava a criminalidade violenta e o narcotráfico "às contradições que opõem morro e asfalto, traficantes e trabalhadores, favelados e cidadãos" (idem, p. 78-79, grifos da própria autora).

Como resultado desse debate público coordenado pela imagem da cidade em "guerra", as favelas cariocas tornaram-se, difusa e imprecisamente, o foco representativo principal e quase exclusivo da violência urbana na cidade (Rocha; Palermo, 2015, p. 26), gerando um impacto negativo de grande monta nos direitos dos favelados, tanto do ponto de vista social como político.

Em síntese, no plano social, a representação da cidade em "guerra" transpôs para os moradores de favelas um estigma que eles tinham alguma ligação/conivência com traficantes de drogas (Machado da Silva e Leite, 2008, p. 73-76; Souza, 2012, p. 120). Além disso, as ações policiais violentas realizadas em favelas eram interpretadas por parcela da sociedade como necessárias e as mortes derivadas dessas ações eram vistas como acidentes de percurso (Leite, 2000, p. 82; Fridman, 2008, p. 83).

No plano político, o direito dos moradores de favelas à cidade passou a ser enxergado como uma questão secundária em relação ao combate à 
violência urbana. Assim, ganhou força um constructo discursivo que pregava que primeiramente tinha que se ganhar a "guerra" urbana para que se pudesse pensar em questões atinentes aos direitos dos favelados (Machado da Silva, 2010, p. 296-298). Nessa chave analítica, as favelas passaram a ser encaradas menos centralmente pelo ponto de vista dos direitos de seus moradores e mais substancialmente como um "perigo imediato" (Machado da Silva, 2012, p. 63) para a cidade.

O resultado geral dessas contendas discursivas foi que a violência tornou-se "uma categoria central da agenda pública" (idem, p. 62) e, desse modo, a linguagem da violência urbana acabou pautando parte dos debates públicos, principalmente os que eram vinculados às favelas cariocas. Criou-se, a partir desse contexto, uma gramática da violência que tem sido ativada, não raramente, para se pensar, discutir, representar ou administrar questões concernentes às favelas. Sendo assim, as representações sobre as favelas cariocas e seu lugar na cidade sofreram uma grande transformação quando

[...] as favelas passam a ser tematizadas na linguagem da violência urbana. Nesse momento, o perigo imputado a elas deixa de ser uma questão urbanística, relacionada ao fortalecimento de uma categoria social em franco processo de incorporação socioeconômica e política. As favelas passaram a ser vistas - pouco importa o quão errônea possa ser essa compreensão - como o valhacouto de criminosos que interrompem, real ou potencialmente, as rotinas que constituem a vida ordinária na cidade (Machado da Silva, 2010, p. 297, grifos do autor).

Diante do que foi exposto, a relação que se faz aqui, neste artigo, é que a linguagem da violência urbana encontra na grande imprensa um canal de reverberação que visibiliza significativamente (Thompson, 2014, p. 19-20; Silva, 2010, p. 18; Fausto Neto, 1999, p.13-14) a conexão entre as favelas cariocas e o problema da violência urbana. É, pois, por meio dessas instituições sociais que a supramencionada linguagem ganha um cariz específico, produzindo a construção social de uma realidade (Porto, 2009, p. 217; Aguiar, 2006, p. 76-77; Silva, 2011, p. 2) que situa esses lugares de moradia num patamar de perigo imediato para a cidade.

Como desdobramento, postula-se que a compreensão do lugar das favelas na cidade é dependente, em alguma medida, do entendimento acerca do papel das grandes mídias que organizam a percepção social e, por conseguinte, reverberam representações e estigmas sobre esses lugares, criando uma agenda pública (Aguiar, 2006, p. 77; Palermo, 2014a, p. 121; Rondelli, 2000, p. 156) 
que situa essas localidades como um problema urbano suscetível de obstar o andamento regular das rotinas na cidade.

É por essa linha de raciocínio que se pode identificar que a maior parte das matérias divulgadas pelo Extra e $O$ Globo, no período pesquisado, enquadram a favela Santa Marta na linguagem da violência urbana. E fazem isso evidenciando especificamente duas matrizes discursivas: ora acionando a "metáfora da guerra" (Leite, 2000, p. 78-80) ou a ideia de "militarização da questão urbana" (Souza, 2012, p. 121), por meio de um discurso que prega que o fim da presença dos traficantes e dos confrontos armados levaria efetivamente a "paz" às favelas ocupadas (Rocha; Palermo, 2015, p. 38); ora conferindo maior preponderância ao repertório verbalizado pela polícia militar, através da estruturação de um discurso que incorpora a "concepção intelectual e prática das UPPs pela polícia carioca" (Almendra, 2014, p. 74), o que produz, por parte da mídia, a legitimação acrítica das ocupações policiais como algo a ser aceito pelos moradores das favelas.

Portanto, seja mobilizando um ou outro repertório (ou combinando ambos), pode-se propor que, em sentido geral, a principal similaridade identificada na cobertura das mídias pesquisadas situa-se no enquadramento temático que majoritariamente as reportagens apresentaram, pois se trata de uma abordagem ancorada nos "repertórios da linguagem da violência urbana e sua metáfora da guerra." (Machado da Silva, 2015, p. 13).

Isso ocorre porque o enquadramento que fundamenta as matérias publicadas enfoca primordialmente na ocupação policial como uma "auspiciosa" vitória sobre o tráfico de drogas (O Globo, Editorial, 3 dez 2008, p. 6), o que permitiria, nessa perspectiva, a ocupação da favela em tempo integral, a fim de manter a área sob controle do estado. Nesse sentido, vale chamar a atenção para o que Ramos e Paiva (2007, p. 77, grifos meus) afirmam:

O mea culpa da imprensa pela cobertura estigmatizante que realiza sobre favelas e periferias é um dos poucos consensos encontrados na pesquisa do CESeC. A maioria dos profissionais [que atuam na mídia] ouvidos reconhece que os seus veículos têm grande responsabilidade na caracterização dos territórios populares como espaços exclusivos da violência. Ao mesmo tempo, admite que a população dessas comunidades raramente conta com a cobertura de assuntos não relacionados ao tráfico de drogas e à criminalidade.

Em razão do exposto, pode-se propor que as coberturas do Extra e $O$ Globo representam, direta ou indiretamente, uma função política (Silva, 2010, p. 135-158; Palermo, 2014a, p. 131), visto que se pode interpretar que 
a homologia nos enquadramentos temáticos realizados pelos impressos tem ligação direta com a construção discursiva que situa as favelas como um "problema" ligado - quase que univocamente - ao perigo para a cidade. Dessa forma, reiteram e atualizam a linguagem da violência urbana em tempos de ocupações policiais de favelas para fins de "pacificação".

Cumpre ainda destacar, enfaticamente, que a cobertura das mídias pesquisadas se pauta pelo discurso que valoriza o ponto de vista normativo institucional-governamental, com vistas a expressar um distanciamento e uma neutralidade, a fim de tentar o diálogo com um público de grande amplitude. Nesse sentido, vale ressaltar que o recurso mais utilizado pelos jornais investigados é se apropriar das informações, dados, explicações e das representações das favelas cariocas que são acionadas pelos integrantes do estafe do governo.

Ao selecionarem as ações do estado e darem voz aos seus comandantes, esses impressos efetivamente cumprem, por um lado, uma função social de prover informações à população. Isso não se deve negar. Mas, por outro ângulo, por sobrevalorizarem esses dados informativos, contribuem para fixar as favelas cariocas, difusamente, como protagonistas quase exclusivos da violência (cf. Ramos e Paiva, 2007, p. 77), o que produz a ratificação de estigmas, na medida em que sancionam, predominantemente de forma acrítica, juízos, dados e sentidos sociais divulgados por integrantes do governo. Terminam, assim, atuando de forma legalista, negligenciando ou deixando em segundo plano a sensibilidade social, ${ }^{22}$ como, por exemplo, as que remetem às demandas de alguns setores da sociedade, sobretudo os que se localizam nos "territórios da pobreza" (Machado da Silva, 2010, p. 286).

Portanto, ao utilizarem um tom que se posta como politicamente correto, adotando eminentemente a perspectiva oficial, lançam uso de recursos que buscam a amplitude discursiva, a fim de agradar diversos setores da sociedade, muito embora se preocupem mais centralmente com as expectativas de seus leitores. Ao atuarem dessa forma, as mídias investigadas emprestam um cariz específico à linguagem da violência urbana, na medida em que elas priorizam o ponto de vista da organização governamental, situando as favelas como as responsáveis primazes pela violência urbana.

\footnotetext{
${ }^{22}$ Deve-se deixar bem claro que as críticas e os argumentos ativados no artigo não devem ser interpretados como uma questão de falta de ética da imprensa analisada. Efetivamente, não se trata disso. Trata-se de chamar a atenção para o ângulo predominantemente adotado. Por isso a crítica se dirige substancialmente para a necessidade de se dar maior equilíbrio às vozes dos atores sociais envolvidos.
} 


\section{Considerações finais}

A pesquisa que foi realizada nos jornais impressos $O$ Globo e Extra, no período referente à ocupação policial realizada na favela Santa Marta, em fins de 2008, identificou uma semelhança geral e algumas diferenças singulares na cobertura dessas mídias. O principal argumento teórico-metodológico desenvolvido ao longo do artigo sustentou que explicar as nuanças do trabalho desses jornais necessariamente passa pela compreensão analítica que envolve a produção, circulação e consumo desses veículos.

A escolha realizada para a análise dessas coberturas centrou-se, principalmente, na pressão que é exercida pela posição do leitor na organização do discurso das mídias investigadas. Sendo assim, as diferenças flagradas na pesquisa foram explicadas pela intrínseca relação entre produção dos impressos e as pressões discursivas que um público especificamente projetado pelos jornais - os leitores e suas expectativas - exerce sobre a forma de escrita, a hierarquização de enquadramentos temáticos e a seleção de conteúdos.

A semelhança geral que pode ser notada nas reportagens de um e outro periódico se relaciona à ênfase na ocupação militar (policial) da favela Santa Marta. Os dois impressos pesquisados têm, primordialmente, essa linha matricial de sentido. É possível afirmar que essa similitude tem relação direta e dialógica com um público mais geral, genérico, ou seja, liga-se aos repertórios em torno da linguagem da violência urbana.

Visando apontar um fundamento mais global que emergiu nesta pesquisa realizada nos jornais Extra e $O$ Globo, defende-se que, nos enquadramentos comuns aos periódicos, há uma espécie de "parceria" (ainda que não intencional e formalmente estabelecida) entre a publicação desses impressos e as informações, dados, explicações e representações institucionais providas por integrantes do governo.

A partir do acompanhamento das reportagens, depreende-se que a escolha das notícias ou a seleção do que foi tornado público teve, de forma prevalecente, ligação - deliberada ou inadvertidamente - com a perspectiva governamental. Trata-se de um recurso de trabalho/criação jornalística que visa revelar isenção, objetividade e transparência, de modo que se produz, nessa lógica, uma autolegitimação discursiva da mídia que acaba minimizando as polêmicas sociais, haja vista que se parte de um ponto de vista que é legal e também racional (baseado na perícia e tecnicismo).

Portanto, com vistas ao diálogo com uma percepção social genérica, que tem ligação com o complexo circuito social dos impressos analisados, pode-se deduzir que essas mídias adotaram como pauta nuclear os discursos ligados à 
estrutura governamental. Ao procederem assim, não somente reverberam uma perspectiva quase monolítica sobre a ocupação da Santa Marta, mas também acabaram por reiterar representações sociais sobre as favelas que são derivadas de premissas governamentais impregnadas e eivadas de estigmas sociais.

Para substancializar essa linha crítica de raciocínio, deve-se alertar que a história das favelas cariocas nos mostra o quanto seu tratamento/administração pelo estado foi referenciado nas representações desses espaços pelo viés da subalternidade, haja vista que eram definidos como um dos "problemas" de grande soma para o desenvolvimento da cidade (pf. Parisse, 1969; Leeds e Leeds, 1978; Valla, 1986; Burgos, 1998; Machado da Silva, 2002; Valladares, 2005).

Pode-se concluir que esses discursos midiáticos, alicerçados basicamente na chave da auspiciosa ocupação militar ( $O$ Globo, Editorial, 3 dez. 2008, p. 6), contribuem para fazer a intermediação e intercâmbio entre a perspectiva institucional-governamental e as percepções de parcela da sociedade, contribuindo para fechar o circuito que estrutura a linguagem da violência urbana, oferecendo um cariz específico a esta última. Nessa linha, as favelas são tratadas como um "problema" ligado a um "perigo imediato" (Machado da Silva, 2012, p. 63) para a cidade, o que estabiliza esses lugares de moradia - numa nova conjuntura cujas promessas se arvoram em ser "pacificadoras" - tanto como um "problema" motriz da violência urbana quanto, ao mesmo tempo, contribui para criminalizar seus moradores (Machado da Silva, 2010, p. 297).

Em vista desses resultados que foram depreendidos da pesquisa, cumpre chamar a atenção que repensar as representações e a aquiescência da sociedade para o "papel da organização institucional da atividade repressiva realizada pela polícia" sobretudo em "territórios da pobreza" (Machado da Silva, 2010, p. 285, 286), bem como refletir criticamente acerca das representações das favelas cariocas (Palermo, 2013, p. 327-328) e rediscutir o estatuto da linguagem da violência urbana constituem-se em operações analíticas que passam necessariamente (não somente, é claro) pela produção de avaliações críticas ao trabalho da imprensa, especialmente a denominada grande mídia. Afinal, esses "agentes [...] desempenham a função legítima [...] de elementos definidores daquilo que é ou não relevante, daquilo que é ou não, portanto, um 'problema público'” (Silva, 2011, p. 3, grifos do autor).

É importante deixar claro que essa proposta não se pauta no pressuposto de que a imprensa é capaz de impor uma visão que manipula completamente a sociedade, mas sim objetar que a mídia tanto é influenciada pela sociedade, pois organiza a percepção social, como também exerce sua influência na 
coletividade, uma vez que os discursos intentam exercer algum tipo de convencimento, marcando algum tipo de posição. Ora, nesse sentido, produzir uma análise acerca da cobertura da imprensa é tanto dialogar com as percepções e representações sociais, como também é pressionar, discursivamente, a mídia no tocante à reflexão crítica de seu papel social.

Diante desse conjunto de registros e reflexões atinentes à função desempenhada por parcela da grande mídia na sociedade atual - papel este que é de grande relevância na modernidade (Thompson, 2014, p. 23-32) -, deve-se chamar a atenção, finalmente, para a proficuidade das pesquisas acadêmicas que, nuclear e sistematicamente, centralizam os discursos da imprensa como questão primaz de investigação, com o fito de produzir uma avaliação crítica dos discursos desses veículos, bem como da atuação de seus profissionais.

Esse é um dos caminhos bastante proveitoso que viabiliza o pensamento crítico acerca do enquadramento das favelas cariocas na linguagem da violência urbana e, por conseguinte, a situação desses lugares de moradia na cidade. Cumpre reiterar que, a partir da pesquisa realizada nos periódicos Extra e $O$ Globo, um dos principais elementos a ser apreciado, com rigor e cuidado metodológico, é a mídia como uma espécie de "porta-voz" do governo, exercendo um trabalho de cobertura que não adota e incorpora um sentido crítico de observação da amplitude social, política e histórica dos acontecimentos ligados às favelas cariocas.

\section{Referências}

AGUIAR, Leonel Azevedo de. O jornalismo investigativo e seus critérios de noticiabilidade: notas introdutórias. Alceu, v. 7, n. 13, p. 73-84, 2006.

ALMENDRA, Dinaldo. As UPPs, as elites e a imprensa: militarização e consumo no processo de 'pacificação' de favelas do Rio de Janeiro. Revista Paranaense de Desenvolvimento, v. 35, n. 126, p. 61-89, 2014.

BOURDIEU, Pierre. Sobre a televisão. Rio de Janeiro: Jorge Zahar Editor, 1997.

BRANDÃO, Helena Nagamine. I - Conceitos e fundamentos: enunciação e construção do sentido. In: Comunicação e análise do discurso. São Paulo: Contexto, 2013. p. 19-43.

BURGOS, Marcelo Baumann. Dos parques proletários: as políticas públicas nas favelas do Rio de Janeiro. In: Alba Zaluar; Marcos Alvito (orgs.). Um século de favela. Rio de Janeiro: FGV, 1998. p. 25-60.

BURGOS, Marcelo Baumann; PEREIRA, Luiz F.; CAVALCANTI, Mariana; AMOROSO, Mauro. O efeito UPP na percepção dos moradores de favelas. Revista de Ciências Sociais da PUC-Rio, v. 11, p. 49-98, 2011.

CANO, Ignacio; BORGES, Doriam; RIBEIRO, Eduardo (orgs.). Os donos do morros: uma avaliação exploratória do impacto das Unidades de Polícia Pacificadora (UPPs) no Rio de Janeiro. São Paulo: Fórum Brasileiro de Segurança Pública, 2012. 
CEVIS (Coletivo de Estudos Sobre Violência e Sociabilidade. Virtudes e limites das UPPs: uma avaliação socioantropológica (relatório de pesquisa para a Faperj). Rio de Janeiro: Uerj, 2011.

FAUSTO NETO, Antônio. Comunicação e mídia impressa: estudo sobre a Aids. São Paulo: Hacker Editores, 1999.

FLEURY, Sônia. Militarização do social como estratégia de integração: o caso da UPP do Santa Marta. Sociologias, v. 14, n. 30, p. 194-222, $2012<10.1590 /$ S151745222012000200007>.

FRIDMAN, Luis Carlos. Morte e vida favelada. In: Luiz Antonio Machado da Silva (org.). Vida sob cerco: violência e rotina nas favelas do Rio de Janeiro. Rio de Janeiro: Nova Fronteira, 2008. p. 77-98.

LEEDS, Anthony e LEEDS, Elizabeth. A sociologia do Brasil urbano. Rio de Janeiro: Zahar, 1978.

LEITE, Márcia Pereira. Entre o individualismo e a solidariedade: dilemas da política e da solidariedade no Rio de Janeiro. Revista Brasileira de Ciências Sociais, v. 15, n. 44, p. 73-90, 2000.

MACHADO DA SILVA, Luiz Antonio. A continuidade do 'problema favela'. In: Lucia Lippi Oliveira (org.). Cidade: história e desafios. Rio de Janeiro: Editora FGV, 2002. p. 220-237.

MACHADO DA SILVA, Luiz Antonio. 'Violência urbana', segurança pública e favelas: o caso do Rio de Janeiro atual. Caderno CRH, v. 23, n. 59, p. 283-300, 2010 $<10.1590 /$ S0103-49792010000200006>.

MACHADO DA SILVA, Luiz Antonio. Polícia e violência urbana em uma cidade brasileira. Etnográfica, v. 15, n. 1, p. 67-82, 2011.

MACHADO DA SILVA, Luiz Antonio. A partir do relatório Sagmacs: as favelas, ontem e hoje. In: Marco Antonio da Silva Mello; Luiz Antonio Machado da Silva; Leticia Luna Freire; Soraya Silveira Simões (orgs.). Favelas cariocas ontem e hoje. Rio de Janeiro: Garamond, 2012. p. 51-65.

MACHADO DA SILVA, Luiz Antonio. A experiência das UPPs: uma tomada de posição. Dilemas: Revista de Estudos de Conflito e Controle Social, v. 8, n. 1, p. 7-24, 2015.

MACHADO DA SILVA, Luiz Antonio; LEITE, Márcia Pereira. Violência, crime e polícia: o que os favelados dizem quando falam desse temas? In: Luiz Antonio Machado da Silva (org.). Vida sob cerco: violência e rotina nas favelas do Rio de Janeiro. Rio de Janeiro: Nova Fronteira, 2008. p. 47-76.

MAUAD, Ana Maria; CAVALCANTE, Paulo. História e documento. v. 1. Rio de Janeiro: Fundação Cecierj, 2013a.

MAUAD, Ana Maria; CAVALCANTE, Paulo. História e documento. v. 2. Rio de Janeiro: Fundação Cecierj, 2013b.

MELLO, Marco Antonio da Silva; CUNHA, Neiva Vieira da. Novos conflitos na cidade: a UPP e o processo de urbanização na favela. Dilemas - Revista de Estudos de Conflito e Controle Social, v. 4, n. 3, p. 371-401, 2011. 
MENEZES, Paloma. Os rumores da 'pacificação': a chegada da UPP e as mudanças nos problemas públicos no Santa Marta e na Cidade de Deus. Dilemas - Revista de Estudos de Conflito e Controle Social, v. 7, n. 4, p. 665-684, 2014.

PARISSE, Luciano. Favelas do Rio de Janeiro: evolução e sentido. Rio de Janeiro: Centro Nacional de Pesquisas Habitacionais, 1969.

PALERMO, Luis Claudio. Megaeventos e Unidades de Polícia Pacificadora: representações sobre o lugar das favelas no tecido urbano. Ilha - Revista de Antropologia, v. 15, n. 2, p. 311-330, $2013<10.5007 / 2175-8034.2013$ v15n1-2p311>.

PALERMO, Luis Claudio. Da 'Guerra' no Complexo do Alemão à ocupação da Favela Santa Marta: aspectos de uma política de segurança pública. Ilha - Revista de Antropologia, v. 16, n. 2, p. 115-145, 2014a <10.5007/2175-8034.2014v16n2p116>.

PALERMO, Luis Claudio. A partir da mídia impressa: os objetivos das unidades de polícia pacificadora sob uma perspectiva histórica. Revista Intratextos, v. 5, n. 1, p. $1-28,2014 b<10.12957 /$ intratextos.2014.11440>.

PERALVA, Angelina. Violencia e democracia: o paradoxo brasileiro. São Paulo: Paz e Terra, 2000.

PORTO, Mauro P. Enquadramentos da mídia e política. In: Antonio Albino Canelas Rubim (org.). Comunicação e política: conceitos e abordagens. Salvador: Edufba, 2004. p. 73-104.

PORTO, Maria Stela Grossi. Mídia, segurança pública e representações sociais. Tempo Social, v. 21, n. 2, p. 211-233, $2009<10.1590 /$ S0103-20702009000200010 >.

RAMOS, Silvia; PAIVA, Anabela. Mídia e violência: tendências na cobertura de criminalidade e segurança no Brasil. Rio de Janeiro: Iuperj, 2007.

ROCHA, Lia de Mattos; PALERMO, Luis Claudio. 'O morro está na calmaria': mídia impressa e o repertório da paz no contexto da pacificação. Dilemas: Revista de Estudos de Conflito e Controle Social, v. 8, n. 1, p. 25-40, 2015.

RODRIGUES, André; SIQUEIRA, Raíza. As Unidades de Polícia Pacificadora e a segurança pública no Rio de Janeiro Comunicações do Iser, 2012, p. 9-52.

RONDELLI, Elizabeth. Imagens da violência e práticas discursivas. C. Alberto Messeder Pereira; Elizabeth Rondelli; Karl Erik Schollhammer; Micael Herschmann (orgs.). Linguagens da violência. Rio de Janeiro: Rocco, 2000. p. 144-162.

SILVA, Edilson Márcio Almeida da. Notícias da "violência urbana": um estudo antropológico. Niterói: Editora da Universidade Federal Fluminense, 2010.

SILVA, Edilson Márcio Almeida da. Imprensa e processos de produção da verdade: representações midiáticas das Unidades de Polícia Pacificadora (UPPs) no Rio de Janeiro/Brasil. XI Conlab - Congresso Luso-Afro-Brasileiro de Ciências Sociais, Salvador, 7 a 10 de agosto de 2011.

SOUZA, Marcelo Lopes de. Militarização da questão urbana. Lutas Sociais, v. 29, p. 117-129, 2012.

THOMPSON, John B. A mídia e a modernidade: uma teoria social da mídia. 15. ed. Petrópolis: Rio de Janeiro: Vozes, 2014. 
VALLA, Victor Vincent (org.). Educação e favela. Petrópolis: Vozes, 1986.

VALLADARES, Lícia do Prado. A invenção da favela: do mito de origem a favela. com. Rio de Janeiro: Editora FGV, 2005.

Recebido em: 4 ago. 2015

Aprovado em: 17 dez. 2017

Autor correspondente:

Luis Claudio Palermo

Rua Deputado Soares Filho, 34, apto. 203 - Tijuca

20540-040 Rio de Janeiro, RJ, Brasil 